\title{
1. The United Nations cultural rights mandate: reflections on the significance and challenges
}

\section{Farida Shaheed}

Being the first mandate holder in any area of human rights carries the distinct privilege of freely exploring the scope and normative content of that right as well as the opportunity to lay out a framework to respect, protect, and promote those rights by defining their scope and content. This privilege comes with responsibility and challenges, however. This duality of privilege and challenge as the first mandate holder was an aspect that I was acutely aware of throughout my tenure first as Independent Expert and then Special Rapporteur in the field of cultural rights.

All first mandate-holders undoubtedly face challenges. With respect to cultural rights, however, the usual challenges were compounded by several less usual factors. To start with, unlike other areas of human rights where there is a fairly clear notion of what the human rights violations might be, if not always the solutions, in the case of cultural rights there was little clarity about exactly what this mandate would be about. The ambiguity and lack of precision is reflected in the title of the mandate itself: 'in the field of cultural rights', rather than simply 'cultural rights'. Compare this with, for example, the title of the mandate of the 'Special Rapporteur on the promotion of truth, justice, reparation and guarantees of non-recurrence', which may be a mouthful and overambitious in terms of 'guarantees of non-recurrence', but certainly provides a clear sense of what is being looked at, or even that of the 'Special rapporteur on violence against women - its causes and consequences' which again suggests the scope of the mandate. While ambiguity can also be viewed as an advantage in that it leaves the scope wide-open, it presented a serious challenge. (Early on, we stopped using the formal term except in official documents in favour of the simpler 'cultural rights'). 
The evident skepticism about whether cultural rights were indeed a human right as a distinct area is reflected in the mandate starting off as an Independent Expert position, rather than as a Special Rapporteur. This is especially significant given that cultural rights are clearly enunciated as an integral component of human rights in article 27 of the Universal Declaration of Human Rights and further explicitly elaborated under article 15 of the International Covenant on Economic, Social and Cultural Rights (ICESCR). Several articles of the International Covenant on Civil and Political Rights also relate to cultural rights, as I would later spell out in my reports. The skepticism on the part of many states was evident to me as soon as I assumed the mandate and persisted regardless of the resolution bringing into existence the mandate in 2009, and despite a day of general discussion on the right to take part in cultural life a year earlier in 2008.

Part of the problem stemmed from the paucity of previous work on cultural rights, reflected in the frequent comment prior to my mandate, that cultural rights were a generally underdeveloped area in comparison to other human rights. ${ }^{1}$ Fortunately, some academics were engaged in exploring cultural rights from the international human rights perspective. There were virtually no civil society groups working on cultural rights at all, groups either worked on human rights or on culture. There were a few exceptions dedicated to cultural rights, such as the Fribourg Group that produced the Fribourg Declaration on Cultural Rights in $2007,{ }^{2}$ but this was not a registered entity at that time. ${ }^{3}$ Alternatively groups worked on a particular aspect, as for example, the American Association for the Advancement of Science that narrowly focused on the right to scientific progress and its application, ignoring all other aspects of Article 15 of the ICESCR. The dearth of previous work that could help explore the scope and content of the right rendered the task of explicating the scope and

1 Patrice Meyer-Bisch, Les droits culturels, une catégorie sous-développée des droits de l'homme, Actes du VIIIe Colloque interdisciplinaire sur les droits de l'homme à l'Université de Fribourg (Editions Universitaires Fribourg, Suisse, 1993). See also Elsa Stamatopoulou, 'The right to take part in cultural life', submission to the Committee on Economic, Social and Cultural Rights, day of general discussion on the right to take part in cultural life (E/C.12/40/9), pp. 7-8.

2 Fribourg Declaration on Cultural Rights (2007), available from www.unifr.ch/iiedh/assets/files/declarations/eng-declaration.pdf.

3 The Fribourg Group has since enlarged and initiated the setting up in November 2016 of a new entity called the Observatory on cultural rights and diversity which aims at continuing research, training and advocacy on cultural rights. 
normative content of cultural rights, the purpose of the mandate, all the more challenging.

The paucity of previous work and skepticism are interrelated, of course: the less the work done on a particular aspect of human rights, the less clear its significance is likely to be. For the cultural rights mandate, the uncertainty surrounding what exactly cultural rights were combined with the paucity of related work resulted in an overarching challenge. This was convincing people and, given that the United Nations is comprised of states, state representatives in particular, that cultural rights were human rights meriting attention by making visible cultural rights and their significance in terms of human rights for all. The initial skepticism and uncertainty at the beginning of my tenure was confirmed when it was coming to a close by one ambassador to the United Nations who candidly told me that when I assumed my position 'no one really knew what the mandate was about or what to expect'.

A first breakthrough came in March 2012, when the mandate was converted from an Independent Expert to Special Rapporteur through Human Rights Council Resolution 19/6 and without any comment being made by any state. The lack of comment was seen as significant because at the time the mandate was being established a number of states, while not asking for a vote, had not hesitated to express their skepticism. It is perhaps noteworthy too, that this resolution was tabled before the end of my first three-year tenure and formulated in a way to ensure that I would continue to hold the mandate. The change in attitude was also evident when the mandate started reporting to the Third Committee of the General Assembly in New York, as well as the Human Rights Council in Geneva in 2012. (Although this brought the pressure of writing two thematic reports a year, instead of one.) Having started with a fairly primordial challenge of having to convince people of the value and importance of cultural rights, it is with considerable satisfaction that I can say that at the end of my tenure, the work of the mandate ensured that cultural rights had been accepted as an important area of human rights by states, regardless of whether they agreed with all my reports or not.

\section{KEY PARAMETRES FOR DEEPENING UNDERSTANDING OF CULTURAL RIGHTS}

Given the dearth of materials, developing the cultural rights mandate would have been still more difficult had it not been for the general comment No. 21 (2009) of the Committee on Economic, Social and 
Cultural Rights (CESCR) on the right to participate in cultural life. ${ }^{4}$ The comment was in the final stages of preparation when the cultural rights mandate came into existence and, fortuitously, the perspective of the Committee coincided with my own. The comment resonated deeply with my own thinking in several key aspects. In particular, the understanding that culture is to be considered 'a living process, historical, dynamic and evolving' (para. 11), 'not as a series of isolated manifestations or hermetic compartments, but as an interactive process whereby individuals and communities, while preserving their specificities and purposes, give expression to the culture of humanity' (para. 12), reflected my own thinking. So, too, did the assertion that 'the cultural life of the community' today had to be understood in the plural as 'communities' (pp. 7-9). This seemed to be one of those obvious facts that nevertheless need to be explicated in written text. The general comment served as an important springboard in the initial development of cultural rights under the mandate.

My own understanding was, and remains, that the significance of cultural rights only becomes apparent by moving away from the concept of culture as specific manifestations of self-expression and simultaneously recognizing that culture permeates all human activities and institutions equally, whether artistic expressions or legal systems. ${ }^{5} \mathrm{Cul}-$ ture, I often say, is like a prism through which we perceive, understand and engage with the human, manufactured and natural world around us, and through which we, in turn, are perceived and understood by others. Culture therefore provides people with a sense of self, underpins collective and individual identities alike and is manifested in individual and collective self-expression, understanding and practices. But neither culture nor identity is ever static. What is not explicated in comment No. 21 is that (a) identities, individual as well as collective, are also in a constant state of creation and (b) culture is always a site of contestation over meanings and worldviews in which new understanding, discoveries and

4 UN Committee on Economic, Social and Cultural Rights (CESCR), General Comment no. 21, Right of everyone to take part in cultural life (art. 15, para. Ia of the Covenant on Economic, Social and Cultural Rights), 21 December 2009, E/C.12/GC/21, available at: http://www.refworld.org/docid/ 4ed35bae2.html.

5 See for example, Farida Shaheed, 'The Interface of Culture Custom and Law - Implication's for Women and Activism' in Women's Law in Legal Education and Practice in Pakistan North-South Cooperation (eds), Rubya Mehdi and Farida Shaheed (New Social Science Monograph: Copenhagen, 1997). 
insights confront the old, the established, and the normative. Hence, the normative defined by concepts of culture, is also in a constant state of flux: being created, contested and recreated within the social praxis of diverse groups interacting in all human endeavours in the economic, social and political arenas as well as in what are traditionally understood to be cultural spheres of life.

I also concurred with the Committee's view that cultural rights encompass an aspect of collective rights as well as of individual rights, and that cultural rights may be exercised not only alone, or in association with others but also as a community. ${ }^{6}$ This has a particular significance for indigenous and local communities, but also for all others as culture itself is a collective process. The collective aspect of cultural rights was also taken up by the Committee in its general comment No. 17 in reviewing the moral and material rights over authorship over any scientific, literary or artistic production of which he or she is the author with reference to the ICESCR, reflecting the fact that some authorship is collective, rather than individual - something I also elaborated on in several of my thematic reports, notably the reports on cultural heritage, the right to enjoy the benefits of scientific progress and its applications, and copyright.

Apart from the resonances with my perspective on cultural rights, general comment No. 21 provided a pivotal and practical insight. This was the clarification that the right to participate in cultural life is to be considered as having three distinct aspects: (a) the right to access; (b) the right to participate in; and (c) the right to contribute to cultural life. ${ }^{7}$ Using the basic human rights premise that human rights must apply to all and the yardstick of considering each aspect from the viewpoint of the most disempowered and marginalised, this apparently simple unpacking has proved extremely useful for it implies a series of basic questions to be asked. Questions include, for example, who has access and who does not, and to what is this access? What blocks or enables participation and of which people/groups of people? What does contribution mean, and what is needed to ensure that everyone is able to contribute to cultural life on a basis of equality and without discrimination? These questions proved equally valid for researching the right to enjoy the benefits of

6 See also Jaime Marchan Romero, 'Derechos culturales: la practica del Comité de derechos economicos, sociales et culturales', working paper submitted to the seminar on implementing cultural rights: nature, issues at stake and challenges, p. 5, available at http://www.ohchr.org/EN/Issues/CulturalRights/ Pages/Documentation.aspx.

7 General comment No. 21, supra note 4, para. 15. 
scientific progress and its applications, as for artistic freedoms, history teaching and memorialisation processes, advertising, etc. and have greatly facilitated the elaboration of normative content of cultural rights.

\section{CULTURE, CULTURAL DIVERSITY AND CULTURAL RELATIVISM}

A separate challenge in terms of developing the cultural rights mandate concerned the unmistakable initial concern of numerous states that cultural rights would translate into cultural relativism, thereby undermining the universality of human rights; as evident in the nature of the questions my first two reports evoked. Presumably this concern was related to the terms of reference of the mandate 'to study the relationship between cultural rights and cultural diversity'.

This I saw as less challenging. While I am convinced that rights can only be fully enjoyed when they become integrated into a people's culture, I have long maintained that no society ever has a singular culture and that cultures relate to power. Regardless of other constituent factors, every society in the world has a dominant culture, promoting the viewpoints and perspectives of those with the power to enforce their norms and impose sanctions for transgressions, as well as subaltern cultures of those with less power or those contesting the current configurations of power. ${ }^{8}$ Collective identities are inextricably linked to the underlying structures and dynamics of power related to accessing and exercising control over economic, political and cultural resources in every society. Consequently, from the very first report I have stressed that not only is culture dynamic, it is inherently linked to issues of power. Power differentials impact the ability of individuals and groups to effectively contribute to the identification, development and interpretation of what should be considered as a common 'culture' both in terms of shared cultural heritage from the past and in terms of contemporary cultural life. Equality and diversity within each community (however defined) is just as crucial as equality and diversity across communities for belonging - to a family, community or society - does not automatically confer equality within that community. Consider, for example, the

8 Farida Shaheed, 'Violence Against Women Legitimised by Arguments of 'Culture' - Thoughts from a Pakistani Perspective.' in Due Diligence: The Responsibility of the State for the Human Rights of Women (ed.) Carin Benninger-Budel (Netherlands: Martinus Nijhoff Publishers, 2008). 
situation of women or persons with disabilities, or those with less economic power in any community.

This makes it imperative to deconstruct 'the community'. Instead of presuming a homogenous community in which everyone lives happily together as equals, it is vital to analyse both who is assumed to be the authoritative voice of 'the' community and by whom, in particular the state, this is assumed. Demystifying the construct of 'the community', which is so closely associated with culture, reveals who defines and decides what the values of a particular community are, helping to identify the positive obligations of the state. With respect to states, it is important to remember that there are more ethnic groups than nation states and that 'nations, and ethnic groups and cultural communities are ideologically plural even if they share common cultural mores' ${ }^{9}$ From the perspective of human rights norms and standards, it is equally important to bear in mind the tendency of nation states to protect dominant nations or groups. ${ }^{10}$ The tendency to protect dominant groups becomes especially problematic, for example, when the voice of 'the' community is taken to exclusively mean a few patriarchs who have power, as elaborated in my report on the enjoyment of cultural rights by women on an equal basis with men. ${ }^{11}$ The presumption that certain patriarchs (or unelected others) are entitled to speak for all, is all the more problematic given that this tendency persists even in states which otherwise uphold the democratic norm of people voting in their representatives. It is incumbent on states to ensure, as a positive obligation, that everyone has an equal opportunity to access, participate in (which has to include decision-making) and contribute to cultural life.

In terms of diversity, I also stress that individuals are not binaries, the either/or configurations of statistics. In reality, each individual is the bearer of a multiple and complex identity which makes her or him a unique human being while simultaneously enabling her/him to be part of communities of shared culture (see A/HRC/14/36, para. 23). This complex identity is the result of multiple processes of socialisation but equally results from engagements and interactions with the world around us and new stimuli that can evoke a rethinking of received wisdoms and

9 Ephraim Nimni, 'Collective dimensions of the right to take part in cultural life', submission to the Committee on Economic, Social and Cultural Rights, day of general discussion on the right to take part in cultural life, (E/C.12/40/17), p. 8.

Ibid., pp. 10-11.

11 Report 2012 - 'The enjoyment of cultural rights by women on an equal basis with men', A/67/287. 
ways of viewing ourselves, others and our surroundings. While an individual's identity showcases uniqueness, the collective identities emphasise similarity. Collective identities never encompass all the characteristics of any individual: the use of the pronoun 'we' privileges only certain parts of individual identities, selecting specific markers of a complex personal identity that highlight a link with a particular group of people. In many ways 'we' is a social construct as it only comes into play vis-à-vis another. Nevertheless, this social construct plays a central role in the concepts and processes of inclusion/ exclusion that define who we are and who we are not; who the other(s) is/are; what we can and cannot do and what we expect the other to do or not do.

Still, people are simultaneously part of several communities of shared cultural values. The specific implications are that cultural rights must translate into ensuring that every voice is given an opportunity to be heard equally, in particular those who are marginalised, disempowered and with least opportunities of voicing their concern. Rights must underpin each person's ability to simultaneously be part of as many or as few communities as they choose as well as joining, leaving and (re)joining these at will; to critique the existing parameters and mores of all the cultural communities in which they want to participate and be able to freely create new communities of shared cultural values, and to do all this without fear of punitive action.

It is of paramount importance to distinguish cultural rights from culture per se even though cultural rights are closely and inherently linked to culture, for it is the failure to distinguish between the two that opens the door to cultural relativism. The conflation of culture with cultural rights has meant that throughout my mandate I found myself repeating that the mandate was not about preserving culture as it is or even safeguarding cultural heritage, however valuable this may be. This is the remit of UNESCO. Cultural rights are also certainly not about traditions, except for 'The greatest tradition [which] is the tradition of reinventing tradition', as the social psychologist Ashish Nandy says. ${ }^{12}$ The mandate is about ensuring that the necessary conditions exist for everyone to access, participate in and contribute to cultural life on a basis of equality and without discrimination; to question existing traditions and create new ones. This means ensuring equal opportunities to be heard and to experience cultural life as a participant and to be a contributor to it.

12 See Ashish Nandy The Intimate Enemy - Loss and Recovery of Self under Colonialism (2nd edn, Oxford India Paperbacks: New Delhi, 2009). 
Every culture, contemporary as well as past, has aspects to it which are not in keeping with human rights standards and all cultures violate human rights at some point or aspect. Therefore, as stated by Adbulaye Sow, 'it is myopic [and] misinformed to say that cultures are essentially pro or anti-human rights. They are in fact neither of the two and a fertile arena for contestation'. ${ }^{13}$ All societies must strive to reorient culture to be in keeping with human rights. Nowhere is this more apparent than in the case of gender given that culture has consistently been used to keep women, girls and persons of other genders disempowered, and to deny their rights.

\section{THE CHALLENGE OF GENDER AND CULTURE}

Culture is often used in the context of the Convention on the Elimination of all forms of Discrimination Against women (CEDAW) to explain the lack of progress. This, despite article 5 under which states are to:

take all appropriate measures to modify the social and cultural patterns of conduct of men and women, with a view to achieving the elimination of prejudices and customary and all other practices which are based on the idea of the inferiority or the superiority of either of the sexes or on stereotyped roles for men and women. ${ }^{14}$

Indeed, knowing how women are pushed into participating in all kinds of harmful practices in the name of culture, my very first statement as a mandate holder stressed that the right to participate in cultural life includes the right not to participate in any cultural event, ritual or process that undermines human dignity.

As the mandate resolution explicitly calls for a perspective on gender (as well as persons with disabilities), it was interesting that early on in my mandate, at one of my first side events on women and cultural rights, some states commented that while the mandate should have a perspective on gender, it should not focus on gender per se. My response was that even if the resolution had not called for this perspective, I would have included gender because gender is central to all cultures everywhere for it is only one of three incontrovertible facts of life, the other two being

13 Abdulaye Sow. Le droit de participer à la vie culturelle. (E/C.12/40/17) pp. 8-9.

14 Convention on the Elimination of All Forms of Discrimination against Women (CEDAW), available at http://www.un.org/womenwatch/daw/cedaw/text/ econvention.htm. 
birth and death. Gender is not only a social construct; it is a cultural construct present in every society and community, large or small, with its accompanying gender rules: the permissible and impermissible, the laudable and the condemnable, as well as punitive actions for transgressions. ${ }^{15}$ It is therefore impossible to speak of cultural rights and ignore gender.

The key role of culture in imposing and keeping in place patriarchal structures and systems to the detriment of women and girls has been written about at length. There is no doubt that women are prevented from accessing as well as participating in cultural life through restrictions imposed in the name of cultural practices. Culture is used to justify numerous other violations of rights: being subjected to various forms of violence; denied political, economic and educational rights for example. In terms of cultural life, the ability of girls and women to contribute to cultural life is impeded by cultural restrictions as well as not having the wherewithal (resources and opportunities) to explore and develop their creativity, and it is often impossible for women to challenge gender norms or leave their communities without fear of punitive actions. Culture does not exist outside human communities; it is determined by people and the rules and structure and systems put into place.

From the perspective of developing the mandate, the challenge this presented was that most women's rights activists conceived of culture as primarily an obstacle to women's rights. Hence, in 2009, no activists were looking at cultural rights from a gender perspective. As a feminist and long-time women's right activist one of my concerns on assuming the mandate was to explore whether and how the lens of cultural rights could help to tackle the complex interface of culture and women's rights. Having researched the CEDAW committee reports and comments, and having concluded that it would be difficult to always prejudge what exactly could be categorised as harmful practice in a given context, I started advocating a paradigm shift: from viewing culture as an obstacle to women's rights to demanding equal cultural rights of women and girls at par with men and boys within the first year of the mandate. I shared this perspective with civil society groups focused on women's rights and also met informally with the CEDAW Committee on a couple of

15 See for example, Farida Shaheed, 'Citizenship and the Nuanced Belonging of Women', in Scratching the Surface: Democracy, Traditions, Gender (ed.) Jennifer Bennett (Lahore, Heinrich Böll Foundation, 2007). See also Nira Yuval-Davis, The Politics of Belonging: Intersectional Contestation (London, Sage, 2011). 
occasions, in the hopes that the Committee would be able to adopt this new perspective. When it became evident that the Committee's preexisting work commitments mean this could not happen in the near future, I was persuaded to write a report on the topic to help identify specific questions that can help to hold states accountable to their international obligations. This has the net advantage of holding states accountable to their international obligations while avoiding the likely contentious discussions around which culture may be 'better' or 'worse'.

\section{DEFINING THE PARAMETRES OF CULTURAL RIGHTS AND KEY LESSONS}

Several factors contributed to defining the scope and content of cultural rights. If one driver was examining the various parts of article 15 of the ICESCR to explore how to translate these into more concrete measures, equally important catalysts for content and scope emerged in the course of country visits and interactions as well as communications regarding a violation of rights. Examining and elaborating on one right, led to explorations and reports on other aspects. For example, the pivotal role of history that led to two consecutive reports on history teaching and memorialization processes, was catalysed by meeting people on every country visit striving to retrieve, document and make known their history both as a means of strengthening their own identity and so as to make others acknowledge this history and therefore, them as a people. In parallel, I also met people contesting the contents and/or the way in which history was currently being taught, or simply feeling left out in the educational process that defines who 'we' are in a particular country. The report on artistic freedoms, for its part, was galvanized by the increasing number of communications I started receiving as a mandate holder reporting violations of the rights of people engaged in artistic expression.

A significant challenge in defining the scope of the mandate was the constant reference to science as well as culture, scientific progress as well as artistic creativity in both the Universal Declaration and even more explicitly in article 15 of the ICESCR. The CESCR had examined and elaborated on very specific aspects such as the moral and material interests and copyright issues, but had not explored what the right to science as such meant. Hence, when soon after assuming my mandate, someone suggested to me that I should write a report on this aspect, I was reluctant. This was not only because this was definitely outside my own comfort zone, but also because the literature I perused revealed a tendency to focus either on 'culture' or 'science'. Indeed, it was 
suggested that, depending on the writer's perspective, either culture or science had been added merely because it was in UNESCO's mandate. When I consulted the Committee for possible guidance, the response was not encouraging. Writing such a report was seen as difficult as there was no case law on which to build. Nevertheless, although hesitant, I decided to write a report anyway as I believe one of the responsibilities of a mandate holder is to explore difficult issues.

There were two important catalysts for my understanding of the right to science; first, an article by Lea Shaver gave me invaluable insights, and led me to adopt her term 'the right to science and culture'. ${ }^{16}$ The second catalyst was a fundamental question posed by Mara Busto of the Office of the High Commissioner for Human Rights (OHCHR) during the expert group meeting on the subject, for which I am extremely grateful. Her question was: What does the right to enjoy the benefits of scientific progress and its application mean beyond the right to health and other aspects of scientific inquiry? Thinking about this vital question in conjunction with reading about aspirations being a cultural competency gave me a breakthrough in understanding. The epiphany was that at the core of cultural rights is human creativity, regardless of whether this is in terms of science, technology or artistic expression. The right to science is encompassed in the broader right of all human beings to not only create (an essential part of cultural life), but also to enjoy the fruits of the creativity of others while preserving the right of authors, read as including all manner of creators, to the moral and material benefits of that creativity. As expected, this report was highly praised by a number of states and not at all well-received by others; and the use of the shortened 'right to science' was questioned. It is therefore interesting to note that the term right to science and culture (or culture and science) is now becoming quite common.

Different arcs of investigation helped to continuously further explore and define the scope of the mandate. The artistic freedoms report, for example, brought to light the importance of public spaces as arenas for cultural life and threw up questions regarding who decides on the utilisation of such spaces. This directly led to the subsequent report on advertising, but it also contributed to the report on memorialisation, museums and monuments. The artistic freedom as well as the right to science reports galvanized the work on copyright and the difficult interface of cultural rights and intellectual property laws. Working on

16 Lea Shaver, 'The right to science and culture', Wisconsin Law Review, 2010. 
intellectual property laws was especially challenging and involved a very steep learning curve for me. In like manner, the cultural heritage report led to the later reports on history and memorialization. The development of the reports and accompanying research helped overcome what initially seemed to be an almost insurmountable challenge of defining the scope of cultural rights. Given that culture does permeate all aspects of human life the question was where to draw the line between cultural rights and other human rights.

In terms of normative content, country visits especially brought home several important lessons for furthering cultural rights. Efforts for promoting access to cultural life do exist but there is clearly a need to avoid ghettoization - meaning that it is not sufficient to ensure people's access to their own cultural life. Promoting cultural rights requires a multi-way process. This means that it is not sufficient to merely ensure that a particular group of people have access to their own cultural heritage, such as history or cultural spaces. It is equally important that the majority community learns about the history of minorities and is encouraged to participate in the cultural events and self-expression of marginalised communities - care being taken to ensure that the people whose cultural life is involved are not further marginalised by this. Similarly, the right to contribute to cultural life is a crucial and overlooked aspect, especially for marginalised groups. This was a lesson brought home for me by several people, but especially persons with disabilities who insisted that they want to be able to contribute to cultural life through their own creativity and not merely access the creativity of others.

There were several issues I was unable to explore during my tenure which deserve attention, such as cultural rights in educational institutions, the impact of globalization and development imperatives on cultural rights. The cultural rights of indigenous people and persons with disabilities both deserve full reports. There are two other aspects meriting attention I would like to highlight here. The first is the impact of tourism on people's cultural rights. This is especially important given the current focus on culture as a driver of development. There is a real danger that the push for tourism as a source of income will force people into performing their culture for the sake of others, rather than living it. What this means for human rights is not clear yet. I am not implying that all tourism is bad, just that this is an issue that came to light as already constituting a problem in the research on cultural heritage. The second issue relates to cultural rights in state institutions such as orphanages and foster homes, but equally importantly also prisons and hospitals for medical and psychological treatments. This issue was brought to my attention first by a woman who wrote me a letter regarding welfare 
services and their disregard for her cultural rights, but it also came to light in the course of country visits regarding prisoners not being able to speak in their own language with other prisoners, as this was considered a security risk. These are areas I hope future mandate holders as well as scholars and civil society groups will take up.

\section{THE SIGNIFICANCE OF CULTURAL RIGHTS}

In terms of significance, the fact that cultural rights relate to peoples' identity, self-expression and creativity as individuals, groups of individuals and as communities, places them at the centre of human rights. Furthermore, as highlighted in my report on cultural rights for women on a basis of equality with men, cultural rights are empowering rights that can open access to all other rights for many marginalised groups of people. In the case of women and girls, I am convinced that many other social, economic and political rights simply will not be accessible - or fully enjoyed - until women and girls enjoy cultural rights on a basis of equality with men and boys.

Attesting to the interdependence and interrelatedness of human rights, cultural rights in fact bridge rights enshrined in the International Covenant on Civil and Political Rights as well as under the ICESCR, as clearly reflected in particular in the reports on women, artistic freedoms, history teaching and memorialization processes. When I assumed the mandate, not only did few people understand what cultural rights were, many felt these were 'soft rights' that perhaps would not showcase violations in the same way as other rights. However, precisely because human rights are interdependent, regardless of which particular aspect of human rights is used as a window to examine a particular situation, it will inevitably reveal the same basis of discrimination and exclusions of certain people, even though the specific manifestation of the rights' violations will differ. However, I believe that cultural rights are transformative: they are empowering rights, providing important opportunities for the realization of other human rights. The lack of equal cultural rights, combined with economic and social inequalities, makes it difficult, if not impossible, for people to enjoy personal autonomy, to exercise their civil and political rights, and in particular to participate in the political life of their community or country.

In many ways it is the combined impact of several reports that give weight to the scope and normative content as proposed by the mandate. For example, some questioned the report on the right to cultural heritage because they did not think this particular right constituted a real human 
right. They gained a better understanding when the right to cultural heritage was seen in the context of the later report relating to the right to enjoy the benefits of scientific progress and its applications. For others the importance of cultural heritage and who decides what this is became more evident after the report on women. This report highlighted the crucial role of everyone's right to determine what constitutes cultural heritage, that is, things received form the past that are considered so important that they are to be passed on to future generations. There was an even greater and wider appreciation of the value of cultural heritage when seen in the light of the reports on history teaching and memorialization processes. Indeed, this is an area which has been taken forward by the current mandate holder. In this sense, the accumulative work on the mandate I believe has been greater than its individual parts.

Today, there is an acceptance of cultural rights that seemed almost impossible when I started the mandate. Equally importantly, the reports have led to concrete actions and have been used in support of cultural rights by states and non-state actors alike. The mandate's work has, for example, contributed to the development of cultural policies in several Scandinavian countries. The UN Women regularly refers to the report on women, just as several states have acted upon the recommendations submitted and several non-state actors, such as school principals, have instituted changes in accordance with recommendations. The reports have led to language being adopted in the UN, to more reporting on cultural rights under ICESCR, renewed attention to the right to science and culture, including the intersection with intellectual property laws and to a showcasing of the importance of artistic freedom in an unparalleled way. They have contributed to discussions in the European Parliament. Civil society actors have also used the country reports to take forward their agendas. This leaves me both relieved and with a sense of accomplishment. Nevertheless, cultural rights are all too often still considered to be secondary. Too many people still think of cultural rights as a luxury, which can be compromised when priorities must be set. Nothing could be further from the truth, for cultural rights are essential to people's sense of self as well as future aspirations; they are markers of a vibrant and democratic society and a key ingredient in overcoming conflicts. I hope my work has helped clarify this. As a way of highlighting the crucial role of cultural rights I did suggest to the Committee on Economic, Social and Cultural Rights that, for a while at least, it should reverse the order of reviewing states parties reports: instead of starting with questions about economic rights, it should start with asking questions about cultural rights, then social rights and end with economic rights. 
Finally, I have to say that my six years as mandate holder from November 2009 to October 2015 when my second term ended, was an exciting journey of discovery that confirmed the statement made in the first thematic report that, 'In many aspects, cultural rights are pivotal to the recognition and respect of human dignity, as they protect the development and expression of various world visions - individual and collective - and encompass important freedoms relating to matters of identity'. This is a journey I have made together with Mylène Bidault who worked with me on the mandate at the OHCHR and is as passionate about cultural rights as I am and has worked on the subject in great detail. The journey was made possible thanks to innumerable people whose generosity of spirit humbles me; not just the experts who helped undertake the research, but equally others who went out of their way to share their expertise, time, and insights to move the analysis and thinking on cultural rights forward, both in terms of specific meetings and during my country visits. I have learnt enormously from so many, in the process gaining some wonderful friends. I know that it would simply not have been possible to explicate cultural rights without their invaluable inputs and can only hope that the mandate will continue to enjoy such support, eased by the increasing number of people and groups working on cultural rights and by the fact that the question and skepticism that met the idea of cultural rights is now a thing of the past. 